\title{
Small ventricular septal defect associated with severe pulmonary hypertension
}

\author{
LEONARD C BLIEDEN, * JAMES H MOLLER \\ From the University of Minnesota Hospitals, Minneapolis, Minnesota, USA
}

SUMMARY A small ventricular septal defect in an 18 year old man was shown by serial cardiac catheterisation to be associated with a progressive increase in pulmonary arterial pressure. Surgical closure of the defect had no effect on the increased pulmonary arterial pressure. Whether pulmonary hypertension occurred secondary to the haemodynamics of the ventricular septal defect or as an independent event is uncertain.

The natural history of uncomplicated ventricular septal defect has been well delineated, ${ }^{1-5}$ and most cardiologists agree on a general approach to the management of this condition. For children with ventricular septal defect, a left to right shunt less than 2:1 and a pulmonary arterial pressure less than $40 \%$ of systemic pressures a corrective operation is rarely recommended. 6 We report the case of a patient with a small ventricular septal defect in whom progressive pulmonary vascular disease developed.

\section{Case report}

An 18 year old boy was first seen at the University of Minnesota Hospitals at the age of 4 years because of a murmur initially heard at 4 months of age. He was born at 35 weeks' gestation and weighed $2.6 \mathrm{~kg}$. There were no prenatal illnesses, and the mother had received no drugs. There were no symptoms referrable to the cardiovascular system. At 4 years of age a grade 4/6 pansystolic murmur was audible along the left sternal border and a grade $2 / 6$ diastolic murmur at the apex. The second heart sound was normal. The electrocardiogram showed "mild" biventricular hypertrophy. Cardiac catheterisation (Table) showed a $48 \%$ left to right shunt and a pulmonary arterial pressure of $38 / 14 \mathrm{~mm} \mathrm{Hg}$. The pulmonary and systemic vascular resistances were normal (Rp:Rs being 0.14).

He continued to be asymptomatic, and at 11 years

Requests for reprints to Dr James H Moller, Box 288, University of Minnesota Hospitals, 420 Delaware Street, SE, Minneapolis, Minnesota 55455, USA.

^Present address: Pediatric Cardiology Unit, Beilinson Medical Centre, Petach Tikva, Israel. the auscultatory and laboratory findings were unchanged. Cardiac catheterisation (Table) showed a $35 \%$ left to right shunt, a mean pulmonary arterial pressure of $28 \mathrm{~mm} \mathrm{Hg}$, and normal pulmonary arterial resistance (Rp:Rs 0.20$)$. He continued to be asymptomatic and at 16 years a grade $4 / 6$ systolic murmur was still present in the third and fourth intercostal spaces along the left sternal border. A diastolic murmur was barely audible at the apex. The pulmonary component of the second heart sound was strongly accentuated. The electrocardiogram showed right ventricular hypertrophy and a thoracic radiograph cardiac enlargement and increased pulmonary arterial markings. Catheterisation (Table) showed a left to right shunt of $35 \%$. The pulmonary arterial pressure was increased $(86 / 47 \mathrm{~mm} \mathrm{Hg}$, mean 60 $\mathrm{mm} \mathrm{Hg}$ ). The pulmonary vascular resistance was raised and was nearly half of the systemic vascular resistance. The administration of tolazoline hydrochloride caused an increase in both pulmonary and systemic blood flow and a decrease in both systemic and pulmonary vascular resistance.

Subsequently, he underwent surgical closure of a ventricular septal defect. After operation there were neither symptoms nor intolerance to exercise. A grade $2 / 6$ short systolic murmur was present along the left sternal border. The pulmonary component of the second heart sound was accentuated. Diastole was clear. The electrocardiogram showed complete right bundle branch block. The chest radiograph showed a normal heart size but a prominent main pulmonary artery segment. Repeat cardiac catheterisation showed neither a left to right nor a right to left shunt. The pressure in the pulmonary artery was $60 / 29 \mathrm{~mm} \mathrm{Hg}$ (mean $42 \mathrm{~mm} \mathrm{Hg}$ ). The pulmonary vascular resistance was still increased (Rp:Rs 0.04). 
Table Haemodynamic fondings

\begin{tabular}{|c|c|c|c|c|c|c|c|c|c|c|}
\hline \multirow[t]{2}{*}{ Age (yr) } & \multirow{2}{*}{$\begin{array}{l}\text { Weight } \\
(\mathrm{kg})\end{array}$} & \multirow{2}{*}{$\begin{array}{l}B S A \\
\left(m^{2}\right)\end{array}$} & \multicolumn{3}{|c|}{ Pressures (mm $\mathbf{H g}$ ) } & \multicolumn{2}{|c|}{ Blood flow (l/min) } & \multicolumn{2}{|c|}{ Resistance (dyn $\mathrm{s} \mathrm{cm}^{-5}$ ) } & \multirow{2}{*}{$\begin{array}{l}\text { Left to right } \\
\text { shunt (\%) }\end{array}$} \\
\hline & & & $\begin{array}{l}P A \\
(\text { mean })\end{array}$ & $\begin{array}{l}\text { Mean } \\
\text { wedge }\end{array}$ & $\begin{array}{l}S A \\
\text { (mean) }\end{array}$ & Pulmonary & Systemic & Pulmonary & Systemic & \\
\hline 6 & 19.5 & 0.77 & \multirow{4}{*}{$\begin{array}{l}38 / 14 \\
(24) \\
42 / 22 \\
(28) \\
86 / 47 \\
(60) \\
60 / 29 \\
(42)\end{array}$} & 8 & \multirow{4}{*}{$\begin{array}{l}115 / 75 \\
(95) \\
120 / 78 \\
(93) \\
135 / 75 \\
(90) \\
132 / 78 \\
(102)\end{array}$} & 6.6 & 3.5 & 270 & 1940 & 48 \\
\hline 11 & 37.8 & 1.2 & & 8 & & $19 \cdot 3$ & 16.2 & 240 & 1200 & 35 \\
\hline 16 & 59 & 1.57 & & - & & 8.7 & 6.1 & 552 & 1180 & 35 \\
\hline 18 & 76.4 & 1.85 & & 8 & & $6 \cdot 1$ & $6 \cdot 1$ & 554 & 1345 & 0 \\
\hline
\end{tabular}

BSA, body surface area; PA, pulmonary arterial; SA, systemic arterial.

\section{Discussion}

Our patient with a small ventricular septal defect had the rare finding of associated pulmonary arterial hypertension. Several possibilities have been suggested for the origin of pulmonary hypertension from raised pulmonary vascular resistance. Pulmonary vasoconstriction, considered to be an essential element in the development of pulmonary hypertension, may originate from a large left to right shunt initially present early in life before pulmonary arterial medial involution takes place. Increase in pulmonary venous pressure may produce or maintain pulmonary hypertension. ${ }^{7}$ Additional causes of pulmonary hypertension are upper airway obstruction and living at high altitudes.

Nevertheless, these factors were not present in our patient and were not responsible for the development of his severe pulmonary obstructive disease. There was no history or clinical evidence of a large ventricular septal defect or increased pulmonary arterial pressure in early childhood.

The critical problem is the difficulty in deciding whether the vascular changes occurred secondary to the ventricular septal defect or as a primary phenomenon. It is impossible to distinguish histologically between the findings in obstructive pulmonary vascular disease secondary to a left to right shunt and those observed in the late stages of primary pulmonary hypertension. ${ }^{8}$ When a ventricular septal defect is present pulmonary vascular disease is usually considered to be secondary to the septal defect, but this association must be questioned when the defect is small.

Severe pulmonary vascular disease has been reported in patients with a spontaneously closed ventricular septal defect..$^{10}$ In each patient, however, the ventricular septal defect was initially either of moderate size or large. Therefore the presumed large shunt could have initiated pulmonary vasoconstriction and the subsequent pulmonary vascular disease. Once the process of pulmonary vascular disease has been started it may be unnecessary after a certain stage for the stimulus for the vascular disease to be sustained.

In our patient the ventricular septal defect was closed surgically. Although pulmonary vascular disease develops after surgical closure of a ventricular septal defect, ${ }^{11}$ the defects are usually large and the pulmonary arterial pressure increased from early life.

The case of our patient with a small ventricular septal defect is, therefore, unusual and presents a rare event-the development of pulmonary vascular disease. Whether the pulmonary hypertension occurred secondary to the haemodynamic effects of the ventricular septal defect or as an independent event-that is, primary pulmonary hypertension-is uncertain. We consider that patients with a small ventricular septal defect should be investigated every five years but do not feel this frequency needs to be increased because of the rare occurrence of pulmonary hypertension.

Supported by the Dwan Cardiovascular Learning Center, University of Minnesota Hospitals, Minneapolis, Minnesota.

\section{References}

1 Bloomfield DK. The natural history of ventricular septal defect in patients surviving infancy. Circulation 1964; 29: 914-55.

2 Lucas RV Jr, Adams P Jr, Anderson RC, Meyne NG, Lillehei CW, Varco RL. The natural history of isolated ventricular septal defect. A serial physiologic study. Circulation 1961; 24: 1372-87.

3 Campbell M. Natural history of ventricular septal defect. $\mathrm{Br}$ Heart f 1971; 33: 246-57.

4 Hoffman JIE, Rudolph AM. The natural history of isolated ventricular septal defect with special reference to selection of patients for surgery. Adv Pediatr 1970; 17: 57-79.

5 Stanton RE, Fyler DC. The natural history of pulmonary hypertension in children with ventricular septal defects assessed by serial right-heart catheterization. Pediatrics 1961; 27: 621-6.

6 Rudolph AM. Congenital diseases of the heart. Chicago: Year Book Medical Publishers, 1974: 202-38.

7 Hoffman JIE, Rudolph AM. Increasing pulmonary vascular resistance during infancy in association with ventricular septal defect. Pediatrics 1966; 38: 220-30.

8 Bessinger FB Jr, Blieden LC, Edwards JE. Hypertensive pulmonary vascular disease associated with patent ductus arteriosus. Primary or secondary? Circulation 1975; 52: 157-61.

9 Shem-Tov A, Fine LG, Rotem Y, Neufeld HN. Occlusive pulmonary vascular disease in a child with a spontaneously closed ventricular septal defect. Isr $\mathcal{F}$ Med Sci 1973; 9: 469-76.

10 Bisset GS, Hirschfeld SS. Severe pulmonary hypertension associated with a small ventricular septal defect. Circulation 1983; 67: 470-3.

11 Lueker RD, Vogel JH, Blount SG Jr. Cardiovascular abnormalities following surgery for left-to-right shunts. Circulation 1969; 40: 785-801. 